\title{
Zur Erkennung einer Verfälschung des Traubenweines mit Obst-
} wein hatte $\mathrm{Tuchschmid}$, wie in dieser Zeitscbr. 10, 231 berichtet, eine Vergleichung des Aschengelaltes rorgeschlagen.

Hager*) bemerlit hierzu, diese Angabe sei mit der grössten Vorsicht aufzunehmen, denn der Kalkgehalt mehrerer Weine (z. B. der Aarweine) erreiche häufig $0,08 \%$ und die platragirten Weine haben nicht selten einen doppelt so grossen Kalkgehalt, besonders wenn der verwendete Gyps reich an Kalkcarbonat war. Andererseits liefere der Saft der Birnen und Aepfel höchstens $0,06 \%$ Kalkcarbonat, es sei also nicht ersichtlich, warum der Obstwein nothwendig $3-8$ mal reicher daran sein solle, als der Traubenwein.

F. F. Maye $\mathbf{r}^{* *}$ ) hat sich ebenfalls damit beschäftigt, Unterschiede zwischen Trauben- und Obstwein aufzufnden. Das Resultat seiner zahlreichên Versuche war, dass im Obstwein phosphorsaurer Kalk, im Traubenwein phosphorsaure Kiagnesia vorkommt und sich die beiden Weinarten also durch ihr verschiedenes Verhalten zu Ammoniak erkennen lassen. Setzt man hämlich in einem Probecylinder zu ungefähr 9 Theilen Wein 1 Theil Ammoniakfiüssigkeit, schüttelt um und lässt 12 Stunden lang stehen, so setzen sich bei den Obstweinsorten (Aepfel- und Birnwein) an den Wänden der Probecylinder deutlich Kirystalle fest an, während dies bei den Traubenweinen nicht der Fall ist, sondern bei diesen ein scheinbar nicht krystallinischer Niederschlag entstent, der nicht am Glase haftet. ${ }^{* * *}$ ) Unter dem Mikroskope zeigten sich die ans den Obstweinen erhaltenen Krystalle wie Tafeln mit parallelen Seiten und regelmässigen Zuspitzungen, der anscheinend nicht krystallinische Niederschlag aus den Traubenweinen erschien eberfalls krystallinisch aber in kleinen sternförmigen Gebilden.

Die aus den Obstweinen erhaltenen Krystalle bestehen aus phosphorsaurem Kalk, der aus Traubenwein erfallende krystallinische Niederschlag. ist phosphorsaure Ammonmagnesia.

Auch zur Entdeckung einer Verfälschung des Traubenweines mit Obstwein bält Verf. seine Methode für geeignet, so hat er bei einer Mischung von 1 Birnwein und 3 Tranbenwein nach 12 Stunden die Kryställcben an den Wänden des Probecylinders noch deatlich beobachtet.

*) Pharm. Centralh. 1871, Nr. 25.

**) N. Jahrb. f. Pharm. 36, 314 .

***) Es kommt auch vor, dass beim Traubenwein sich ein glasiger Ueberzug an den Wänden ansetzt, er unterscheidet sich abor gut von den Krystallkörnern des Obstweines. 
Da des Verfassers Versuche blos mit Neckarweinen angestellt sind, so bleibt abzuwarten, ob sich die Methode bei allen Weinsorten wird anwenden lassen.

Ueber Mehlprüfung hat H. Ludwig*) einen längeren Aufsatz veröffentlicht. Derselbe enthält eine Zusammenstellung dessen, was bis jetzt in dieser Beziehung publicirt worden ist, bietet aber nichts wesentlich neues and ich begnüge mich deshalb damit auf die Originalabhandlung: zu verweisen.

Ein neues Verfahren zur Prüfung des Petroleums und anderer Kohlenwasserstofföle auf Entflammbarkeit theilt Dr. van der W e y d e**) mit. Man füllt ein einseitig geschlossenes Glasrohr mit dem zu prüfenden Oele, verschliesst das offene Ende mit dem Finger, kehrt es dann um und stellt es in ein Gefäss mit Wasser, welches durch Mischen von. Fig. 27.

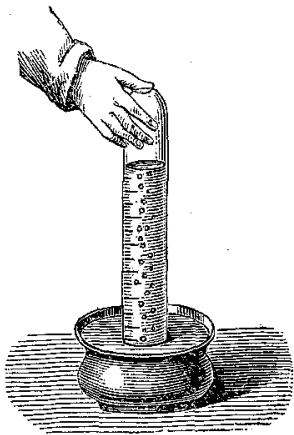
heissem und kaltem Wasser auf $43,3-44^{0} \mathrm{C}$. erwärmt. worden ist; diese Temperatur wird durch zeitweisen Zusatz von heissem Wasser unterhalten (einfacher und sicherer durch Anwendung eines Wasserbades. mit Temperaturregulator H. F.). Sobald nun Gase oder Dämpfe auftreten, sammeln sich dieselben in dem geschlossenen oberen Theile des Rohres an und verdrängen das Oel nach unten. Die Menge dieses Gases gibt einen Anhaltspunkt für die vergleichende Prüfung der verschiedenen Oelsorten und es empfiehlt. sich deshalb die Anwendung eines graduirten Rohres.

Diese Petrolenmprobe ist auf die Thatsache gegründet, dass alle Dämpfe, welche das Petroleum abgibt, rerbrennlich sind und dass, wenn irgend ein Kerosen oder sonstiges Präparat ans Rohpetroleum bei der angenommenen Normaltemperatur von $44^{\circ} \mathrm{C}$. Dampf abgibt, es nicht nöthig ist zu untersuchen, $\mathrm{ob}$ sich derselbe entflammen lässt. Es genügt vielmehr denselben zu sammeln und zu messen. Die Methode in ihrer rohen Form kann natürlich nur höchst ungenaue Resultate geben. Viel besser, wenn auch etwas umständlicher, ist es, die Prüfung des Petroleums mit dem Apparate von Urbain und Salleron anszufuhren, worüber in dieser Zeitschrift 5, 247 berichtet worden ist.

*) Archiv d. Pharm. [2. Reihe] 147; 1.

**) Scientific American 1871, p. 162. 